\title{
1500 V DC Beslemeli Raylı Sistemlerde Gerilim Harmoniği Probleminin AGT Tabanlı Paralel Aktif Güç Fitresi ile Çözümü
}

\author{
Solution of Voltage Harmonic Problem in 1500 V DC Powered Rail Systems by IPT Based \\ Parallel Active Power Filter
}

\author{
Mehmet Taciddin AKÇAY ${ }^{1}$ (i) , Illhan KOCAARSLAN ${ }^{2}$ (it) \\ ${ }^{1}$ İstanbul Büyükşehir Belediyesi, Raylı Sistem Daire Başkanlı̆̆g, İstanbul, Türkiye \\ ${ }^{2}$ İstanbul Üniversitesi, Elektrik-Elektronik Mühendisliği, İstanbul, Türkiye
}

\begin{abstract}
Öz
Enerji kalitesi elektrik güç sistemlerine bağlı ekipmanların verimi ve performansı için gerekmektedir. Enerji kalitesinin ana hedefi yüke ulaşan gerilim ve akım sinyalinin en iyi derecede sinusoidal dalga şekline sahip olmasıdır. Sistemde nonlineer devre elemanlarının varlığı harmoniklerin üretilmesine neden olmaktadır. Harmonikler enerji kalitesini olumsuz etkileyerek sistem performansını düşürmektedir. DC beslemeli raylı sistemler nonlineer elemanlardan oluştuğu için sistemde harmonikler oluşmaktadır. Bu çalışmada 1500 V DC Beslemeli Raylı Sistemlerde Gerilim Harmoniği Probleminin AGT (Anlık Güç Teorisi) Tabanlı Paralel Aktif Güç Fitresi ile Çözümü benzetim yoluyla yapılmıștır. AGT ile zamanda oluşabilecek gecikmelerin önüne geçilebilmesi hedeflenmiştir. Aktif filtre ile klasik filtreleme yöntemleri karşılaştırılarak sonuçlar elde edilmiştir. Sistem analiz edilerek elde edilen sonuçlar grafikler üzerinden verilmiştir. Devre filtreli ve filtresiz olarak çalıştırılarak elde edilen sonuçlar karşılaştırmalı olarak verilmiştir. Her iki duruma ait gerilim THD (Toplam harmonik distorsiyon) değeri hesaplanarak elde edilen iyileştirme ortaya konulmuştur.
\end{abstract}

Anahtar Kelimeler: Analiz, Besleme, Harmonik, Rayl, Sistem

\begin{abstract}
Energy quality is required for the efficiency and performance of equipment connected to electrical power systems. The main objective of the energy quality is that the voltage and current signal reaching the load has the best sinusoidal waveform. The presence of nonlinear circuit elements in the system leads to the generation of harmonics. Harmonics adversely affect energy quality and reduce system performance. Since DC powered rail systems consist of nonlinear elements, harmonics are formed in the system. In this study, voltage harmonic problem in $1500 \mathrm{~V} \mathrm{DC}$ supply rail systems is solved with IPT (Instantaneous Power Theory) based parallel active power filter by simulation. With the IPT, it is aimed to prevent delays in time. The results were compared with active filter and classical filtering methods. The results obtained by analyzing the system are given on the graphs. The results obtained by operating the circuit with and without filter are given comparatively. The voltage THD (Total harmonic distortion) value of both cases was calculated and the improvement obtained was demonstrated.
\end{abstract}

Keywords: Analysis, Feed, Harmonic, Rail, System.

\section{GİRIŞ}

Enerji kalitesi güç sistemlerinin dağıtımında alt sistem verimini etkileyen en önemli faktörlerden biridir. Elektrik güç temini sisteminin ana görevi sinusoidal dalgalı gerilimi sağlamaktır [1]. Şehiriçi demiryollarında cer gücü için tercih edilen DC gerilim beraberinde güç kalitesinde bir takım problemleri ortaya çıkarmaktadır. Enerji kalitesinin düşük olması işletmesel ve ekonomik kayıplarla birlikte aşırı yüklenmeye, güç kayıplarının oluşumuna, aşırı gerilime, aşırı akıma, rezonans olayına ve güç dengesi bozukluklarına neden olmaktadır. Güç kalitesi probleminin çözümü uzun yıllardır üzerinde çalışılan bir konudur [2]. DC sistem yapısında lineer olmayan devre elemanlarını içerdiği için şebekeye gerilim harmonikleri üretilmektedir. Gerilimde, akımda ve frekansta meydana gelen düzensizlik neticesinde güç kalitesi sorunu oluşmaktadır [3]. $50 \mathrm{hz}$ olan temel frekans dişında üretilen harmonikler sistemi olumsuz etkilemektedir. Harmonikler gerilim sinyalinin sinusoidal dalga şeklinden sapmasına neden olmaktadır. Bu durum neticesinde yüke ulaşan gerilim saf sinusoidal şeklinde olmadığı için ekipman performans1 olumsuz etkilenmektedir. DC beslemeli demiryollarında DC gerilim orta gerilim sisteminden elde edilen AC gerilimle sağlanmaktadır. İndirici merkezden elde edilen gerilim doğrultucunun girişine uygun gerilim seviyesine indirilerek dönüşüm gerçekleşmektedir. $1500 \mathrm{~V}$ DC beslemeli demiryollarında bu gerilim $34.5 \mathrm{kV}$ mertebesinden $1.22 \mathrm{kV}$ mertebesine dönüştürülerek doğrultucu girişine aktarılmaktadır. Lineer olmayan devre elemanları 
harmonikler üreterek sistemden reaktif güç çekilmektedir [4]. Reaktif güç ve harmonikler sistem üzerinde olumsuz etki oluşturmaktadır [5]. Reaktif gücün kontrolünde statkom ekipmanı yaygın olarak kullanılmaktadır [6-7]. DC beslemeli demiryollarında doğrultucu sistemi 6 darbeli doğrultucu sisteminden oluşmaktadır. Harmonikli gerilime ait dalga sinyali şekil 1 ile gösterilmektedir. Toplam dalga $50 \mathrm{~Hz}, 150 \mathrm{~Hz}, 250 \mathrm{~Hz}$, $350 \mathrm{~Hz}$ ve $450 \mathrm{~Hz}$ frekansta dalga sinyallerinden oluşmaktadır.

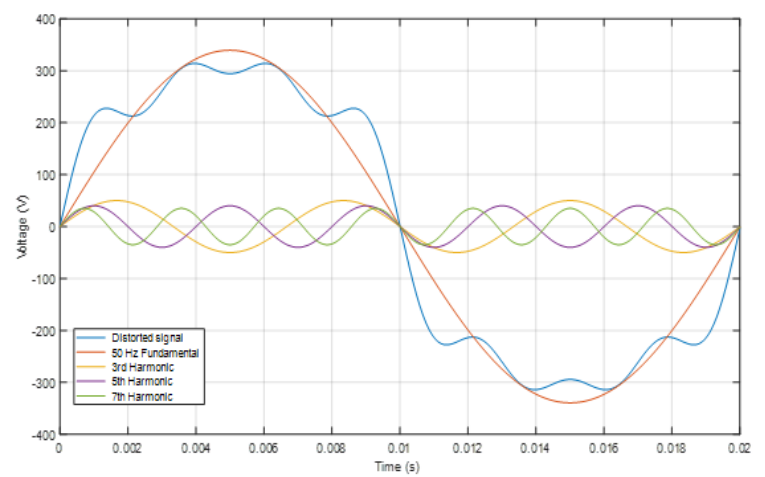

Şekil 1. Harmonikli gerilim sinyali

DC demiryollarında oluşan harmonik probleminin çözümü için bir takım yöntemler kullanılmaktadır. Bunlar pasif ve aktif filtreleme metotları olarak iki kategoride incelenmektedir. Pasif filtreyi oluşturan bileşenler direnç, endüktans ve kondansatör gibi pasif devre elemanlarıdır. Pasif filtreler sistemin spesifik özelliklerine göre tasarlanmakta olup bu tip filtreleme işleminde sistemin belirli frekanslarına göre filtreleme yapılmaktadır. Aktif filtreleme işleminde ise sistemde mevcut durumda, üretilen akım veya gerilim harmoniklerinin hesaplanması ile filtreleme işlemi gerçekleştirilir. Pasif filtreler ile ortadan kaldırılmak istenen harmoniklere uygun frekansta belirlenen endüktans ve kapasite değerleri seçilerek rezonans olayı meydana getirilir ve toplam reaktans çok küçük bir değer alır. İlgili frekansın tanımı endüktif ve kapasitif reaktansları birbirine eşit yapan frekanstır . Kalite faktörü ise, ayar keskinliğini belirlemektedir. Pasif filtreleme işlemi harmonik frekansına uygun olarak şeçilen filtreler sisteme bağlanarak gerçekleştirilmektedir. Ancak bu filtreleme çeşidinde sistemin davranışı statik kabul edildiği için değişken durum koşullarında sistem korumasız kalabilmektedir [8] Aktif filtreler ise dinamik sistem koşullarına uygun çözüm uygulayarak sistemde iyileştirme sağlamaktadır. Aktif filtre lineer olmayan yüklerin oluşturduğu olumsuz durumu ortadan kaldırmak için uygun bir çözüm olarak kullanılmaktadır [9]. Sistemde bulunan harmonik yükler belirlenenler ve belirlenemeyenler olmak üzere iki kategoride incelenmektedir [10]. Aktif filtreleme sistemi ise seri aktif filtre, paralel aktif filtre ve hibrit yapıda aktif filtre olmak üzere çeşitlendirilmektedir. Aktif filtre güç elektroniği devre elemanlarından oluşmaktadır. Aktif filtrenin avantaj1 dinamik koşullara göre yeniden tasarım yapılmasının gerekmemesidir. Aktif filtre DC kapasitör ile DC link gerilim regülasyonu gerçekleştirmektedir [11]. Raylı sistemler işletmesel olarak birçok parametreye bağlı olduğu için dinamik koşullara sahiptir. $\mathrm{Bu}$ özelliğinden dolayı aktif filtreleme yöntemleri raylı sistemler için daha uygun olmaktadır. Aktif ve pasif filtrelerin bazı sisteme bazı olumsuz etkileri de bulunmaktadır. İki tip filtre de sistemde güç artışına neden olmaktadır. Pasif filtreler güç frekansında reaktif güç üretirken aktif filtreler şebekeden çekilen gücün artmasına neden olmaktadır. Bundan dolayı bir sistem için tercih edilirken bu durum da gözönünde bulundurulmalıdır. Aktif güç filtreleri sistemde bulunan harmonikleri ortadan kaldırmasının yanında reaktif güç kompanzasyonu, gerilim ve akım dengesizlikleri problemleri , nötr akımının kompanzasyonu ve şebeke geriliminin düzenlenmesi için de kullanılırlar [12]. Paralel aktif filtre endüstride en çok kullanılan aktif filtre çeşididir [13]. Aktif güç filtreleri; tek fazlı, üç fazlı üç telli ve üç fazlı dört telli tasarımlardan oluşmaktadır. Tasarım tipi ise besleme sistemindeki doğrusal olmayan yüke bağlı olarak, kompanze edilmesi planlanan büyüklüğe göre seçilmektedir [14]. Önceki çalışmalar 1şı̆̆ında güncel teknoloji ile cevap hızları oldukça yüksek aktif güç filtreleri tasarlanabilmektedir [15]. Gerilim sinyalinin kalitesi için gerilim THD değeri hesaplanarak ilgili değerin IEEE-519-1992 standardında belirtilen limitlerin içerisinde kalması hedeflenmektedir. $\mathrm{Bu}$ limitlerin dışında kalınması durumunda ise güç kalitesi problemleri ortaya çıkmaktadır.

(1) eşitliği ile gerilim harmoniği hesaplanmakta olup $\mathrm{V}_{2}, \mathrm{~V}_{3}$ ve $\mathrm{V}_{\mathrm{n}}$ değerleri ilgili frekanstaki harmonik gerilimlerini ifade etmektedir. Bu eşitliğin çözülmesi ile harmonik gerilimlerinin efektif değeri hesaplanmaktadir.

$$
V_{h}=\sqrt{\left(V_{2}^{2}+V_{3}^{3}+\ldots+V_{n}{ }^{2}\right)}
$$

Gerilimin THD değeri hesaplanırken harmonik gerilimlerin efektif değeri temel frekans bileşeninin efektif değerine bölünmesi ile hesaplanmaktadır. Bu denklem (2) eşitliği belirtilmektedir. $V_{h}$ gerilim harmoniğini ifade ederken $V_{1}$ temel bileşeni belirtmektedir. $\mathrm{Bu}$ ifade ile THD değerinin yüzde değeri hesaplanmaktadır.

$$
T H D_{V}=\left(V_{h} / V_{1}\right) \times 100
$$

Bu çalışmada 1500 V DC Beslemeli Raylı Sistemlerde Gerilim Harmoniği Probleminin AGT (Anlık Güç Teorisi) Tabanlı Paralel Aktif Güç Fitresi ile Çözümü yapılmıştır. Modelleme için Matlab/Simulink programı kullanılmıştır. Aktif güç filtresi trafonun sekonder bölümüne paralel olarak bağlanarak filtreleme gerçekleştirilmiştir.

\section{MATERYAL VE METOT}

Bu çalışmada paralel aktif güç filttresi ile $1500 \mathrm{~V} \mathrm{DC}$ 
beslemeli bir hattın trafo merkezinde gerilim harmonik probleminin çözümü araştırılmıştır. Çalışma kapsamında Akagi'nin AGT yöntemi tercih edilmiştir. AGT yöntemiyle tetikleme sinyalleri oluşturularak referans akımlar hesaplanmaktadır. Modelleme için Matlab/Simulink ortamında benzetim yapılmıștır. Aktif filtre için anlık akım, anlık gerilim, anlık güç hesaplamaları yapılarak tasarım oluşturulmuştur.

\subsection{AGT Yöntemi}

1983 yllında Akagi tarafindan bulunan bu teori ile anlık reaktif güç cebirsel olarak hesaplanarak zamanda oluşabilecek bir gecikmenin önüne geçilmektedir. $\mathrm{Bu}$ teori ideal olan ve ideal olmayan akımlarda ve gerilimlerde sürekli ve geçici hal durumlarında geçerli olmaktadır. Clarke dönüşümü olarak bilinen $\alpha-\beta$ dönüşümü 3-fazlı akım ve gerilimleri iki fazlı durağan yapıya çeviren cebirsel bir dönüşümdür [16]. 2-fazlı $\alpha$ $\beta$ durağan referans yapıya çevrildikten sonra anlık güç teorisi kullanılarak yükün gerçek ve sanal güçleri hesaplanmaktadır [16]. Gerilim harmoniğini ortadan kaldırmak için aktif gücün dalgalı bileşeni ve reaktif güç hesaplanmaktadır [16]. Aktif güç filtresi şebekeye gelen harmonikli gerilimi sinüsoidal dalga şekline dönüştürmek için sisteme enjekte etmesi gereken gerilimi referans gerilimlerle bulmaktadır [16]. Aktif filtrenin ürettiği referans gerilimler aşağıdaki eşitliklerde gösterilmiştir. Anlık güç teorisine göre $\square-\beta$ düzleminde hesaplanan referans gerilimler daha sonra ters clarke dönüşümü ile 3 fazlı sistemdeki gerilimlere dönüştürülür. Aktif filtre tasarlanırken bu teoriden yararlanılmıştır. Clarke dönüşümü ise 3 -fazlı akım ve gerilimleri iki fazlı durağan yapıya çevirmektedir [16].

Anlık güç eşitliği (3) ile verilmektedir [16].

$\mathrm{Pa}(\mathrm{t})=\mathrm{VI} \cos \varphi(1-\cos 2 \omega \mathrm{t})-\mathrm{VI} \sin \varphi \sin 2 \omega \mathrm{t}$

Lineer olmayan yüklere ait reaktif ve harmonik güç hesaplamaları (4) ve (5) eşitliği ile verilmektedir [16].

$\mathrm{Q}=3 \mathrm{VI} \sin \varphi$

$\mathrm{D}=3 \mathrm{~V}\left(\mathrm{I}_{2}{ }^{2}+\mathrm{I}_{3}{ }^{2}+\cdots\right)^{1 / 2}$

(6) ve (7) denklemleri ile üç fazlı gerilim ve akım değerlerinin iki fazlı yapıya dönüşümü verilmektedir.

$$
\begin{aligned}
& {\left[\begin{array}{l}
V a \\
V \beta
\end{array}\right]=\sqrt{\frac{2}{3}} \quad\left[\begin{array}{ccc}
1 & -1 / 2 & -1 / 2 \\
0 & \sqrt{3} / 2 & -\sqrt{3} / 2
\end{array}\right]\left[\begin{array}{l}
V s a \\
V s b \\
V s c
\end{array}\right]} \\
& {\left[\begin{array}{l}
I a \\
I \beta
\end{array}\right]=\sqrt{\frac{2}{3}}\left[\begin{array}{ccc}
1 & -1 / 2 & -1 / 2 \\
0 & \sqrt{3} / 2 & -\sqrt{3} / 2
\end{array}\right]\left[\begin{array}{l}
I y a \\
I y b \\
I y c
\end{array}\right]}
\end{aligned}
$$

Şekil 2 ile üç fazlı sistemden iki fazlı yapıya dönüşüm gösterilmektedir.



Şekil 2. $a-b-c$ to $\alpha-\beta$ conversion

(8) ve (9) eşitlikleri ile anlık aktif güç ve anlık reaktif güç hesaplanmaktadır.

$$
\begin{aligned}
& P_{3}=V_{a} I_{a}+V_{\beta} I_{\beta} \\
& \mathrm{Q}_{3}=V_{\beta} I_{a}-V_{\mathrm{a}} I_{\beta}
\end{aligned}
$$

Anlık aktif güç ve reaktif güç eşitliği matris şeklinde yazılırsa (10) ve (11) eşitlikleri elde edilmektedir.

$$
\begin{aligned}
& {\left[\begin{array}{l}
P 3 \\
Q 3
\end{array}\right]=\left[\begin{array}{rr}
V a & V \beta \\
-V \beta & V a
\end{array}\right]\left[\begin{array}{l}
I a \\
I \beta
\end{array}\right]} \\
& {\left[\begin{array}{l}
I a \\
I \beta
\end{array}\right]=\left[\begin{array}{rr}
V a & V \beta \\
-V \beta & V a
\end{array}\right]^{-1}\left[\begin{array}{l}
P 3 \\
Q 3
\end{array}\right]}
\end{aligned}
$$

Referans gerilimler (12) ile hesaplanmaktadır.

$$
\left[\begin{array}{l}
V c a * \\
V c b * \\
V c c * *
\end{array}\right]=\sqrt{\frac{2}{3}} \quad\left[\begin{array}{cc}
1 & 0 \\
-1 / 2 & \sqrt{3} / 2 \\
-1 / 2 & -\sqrt{3} / 2
\end{array}\right]\left[\begin{array}{l}
V c a * \\
V c \beta *
\end{array}\right]
$$

$\mathrm{Bu}$ ifadeyle gerilim değerlerinin cebirsel işlemle $\alpha-\beta$ düzleminden üç fazlı $\mathrm{V}_{\mathrm{ca}} *, \mathrm{~V}_{\mathrm{cb}} *, \mathrm{~V}_{\mathrm{cc}} *$ referans gerilimlere dönüşümü gerçekleştirilerek aktif güç filtresinin ihtiyacı olan tetikleme sinyalleri üretilmektedir [16].

\subsubsection{Sistemin Aklş Şeması}

Clarke dönüşümü ile anlık güçlerin hesaplanmasının ardından eşdeğer referans akımlar ortaya çıkmaktadır. Referans akımlar elde edildikten sonra güç elektroniği devre elemanlarının anahtarlama sinyalleri üretilmektedir. Anlık güçler $\alpha-\beta$ düzleminde akım ve gerilime bağlı olarak hesaplanmaktadır.

$\mathrm{Bu}$ adımların ardından harmonik filtreleme işlemi gerçekleşmektedir. Sistem tarafindan üretilen harmoniklere eşit genlikte ve ters fazda harmonik akımlar üretilerek filtreleme işlemi gerçekleştirilmektedir. Bu adımlar sistemle eşgüdümlü bir şekilde gerçekleşmekte olup zamanda herhangi bir gecikme yaşanmamaktadır.

\subsection{Paralel Aktif Güç Filtre Devresi}

Paralel aktif güç filtre sistemine ait devre modeli şekil 3 ile gösterilmektedir. Aktif filtre güç elektroniği 
devresi, devre elemanları, ve tetikleme sinyalleri için kontrol bloklarından oluşmaktadır. Aktif güç ünitesinin uçlarına ideal güç aktarımı için RL filtre yerleştirilmiştir. Kontrol blokları vasıtasıyla sistem tarafından üretilen harmonik hesaplanarak eliminasyon işlemi gerçekleştirilmektedir. Referans gerilimler hesaplandiktan sonra aktif filtre tarafindan üretilen tetikleme sinyalleri devrede bulunan GTO'ların tetikleme sinyallerini oluşturmaktadır. Harmoniğin etkin bir şekilde kompanze edilmesi için ayrıca devreye paralel kapasitans bağlanmaktadır.

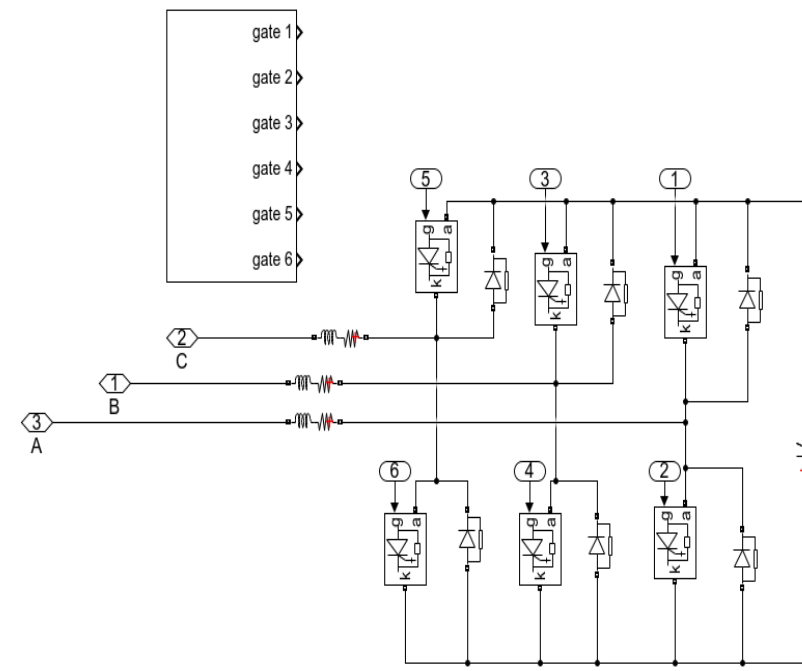

Şekil 3. Aktif filtre devresi

Aktif filtre güç elektroniği devresi GTO’lardan oluşmaktadır. Güç elektroniği alanında yakalanan teknoloji ile transformatör kullanımı azaltılarak kayıplar önemli miktarda önlenmektedir [17]. Devre elemanları seçilirken anahtarlama frekansları ve 1sınma faktörleri hesaba katılmaktadır. Aktif filtrenin üretim kapasitesi seçildiği güç aralığı ile direk bağlantılı olup uygun filtre sistemin optimal güç ihtiyacına göre seçilmektedir. Kontrol blokları yardımıyla her bir kapıya ait tetikleme sinyalleri oluşturulmaktadır.

\subsection{V DC Beslemeli Trafo Merkezi}

$1500 \mathrm{~V}$ DC beslemeli trafo merkezi cer transformatörü ve doğrultucu sisteminden oluşmaktadır. $34.5 \mathrm{kV}$ enerji seviyesinden $1.5 \mathrm{kV}$ DC enerji seviyesine dönüşüm bu merkezde gerçekleştirilmektedir. Şekil 4 ile cer merkezine ait gösterim verilmektedir. Bu dönüşüm her cer merkezinde gerçekleşmektedir. Bir hatta bulunması gereken cer merkezi sayısı hat verileri ve işletmesel özellikler sisteme tanıtılarak cer simülasyonu ile bulunmaktadir.
Traction Substation



$34.5 / 1.22 \mathrm{kV} \mathrm{AC} \quad 1500 \mathrm{VDC}$

Şekil 4. DC Trafo Merkezi

$1500 \mathrm{~V}$ DC beslemeli hatlarda cer merkezi sayıs hesaplanırken EN 50163 ve EN 50122 standartlarına uygun olması hedeflenmektedir. Cer merkezi tarafından beslenen araca ait cer sistemi transformatör, üç fazlı PWM invertor ve asenkron motordan oluşmaktadır [18]. Demiryollarında sistem performansını etkileyen çeşitli işletme parametreleri mecvuttur [19]. Belirtilen standartlar minimum besleme gerilimi ile maksimum ray gerilimi limitlerini belirtmektedir. Hatta meydana gelen gerilim düşümü kontrol edilmediği zaman araç veriminin düşmesi ve işletmenin durdurulması gibi olumsuz olaylar ortaya çıkabilmektedir [20]. DC Beslemeli hatlarda işletme sürekliliği için gerilim kararlılığı çok kritiktir [21]. Demiryollarında yüksek güçlü ekipmanlar kullanıldığ1 için enerji tüketimi yüksek rakamlara ulaşmaktadır [22]. Elektrik güç sistemleri artan güç talebini karşılamak için sınırlarını zorlamaktadır [23]. İşletme trafiği için saptanan sefer sıklığının sağlanabilmesi için elektrifikasyon sisteminin gerekli donanıma ve tasarıma sahip olması gerekmektedir [24]. Bu çalışmada paralel aktif filtre cer merkezinde kullanılarak DC sistem tarafindan üretilen harmoniklerin ortadan kaldırılması amaçlanmıştır.

\subsection{Paralel Aktif filtrenin Devreye Bağlantı Modeli} Paralel aktif filtre sisteme cer merkezinde cer trafosunun seconder tarafından bağlanarak sisteme akım enjekte edilmektedir. Bu çalışmada üç fazlı parallel aktif güç filtresi kullanılmıştır. DC devre tarafindan üretilen harmoniklerin $\mathrm{AC}$ gerilim bölümünde eliminasyonu gerçekleştirilmiştir. Sistem bağlantısıyla ilgili devrenin bağlantı şeması şekil 5 ile gösterilmektedir. Cer transformatörünün sekonder girişine bağlanan paralel aktif filtre devresi sisteme VI ölçüm bloğu üzerinden bağlanmıştır. Nonlineer yük tarafından üretilen harmonik kadar akım sisteme bu bölümde enjekte edilerek harmonik eliminasyonu gerçekleşmektedir. Ölçüm bloğundan sonra DC iletim hattı için gerekli DC gerilimin üretildiği redresör sistemi, LC filtre şekilde görülmektedir. Hat 1 ve hat 2 iletim hatlarına bağlantılar ise $\mathrm{R}$ dirençleri ile gösterilmiştir. 


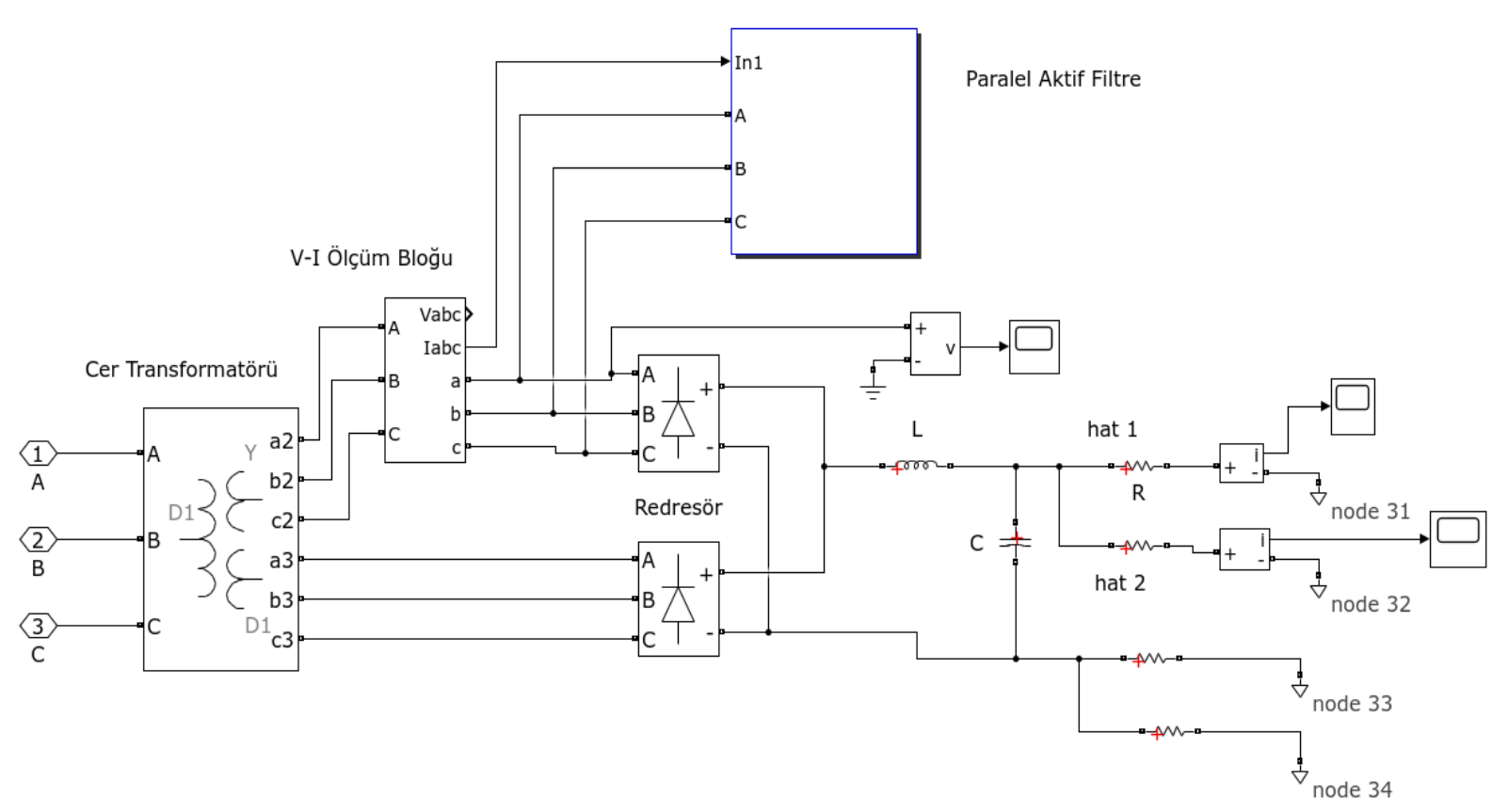

Şekil 5. Paralel Aktif Filtre Bağlantısı

Bağlantının sekonder kısma yapılmasıyla sistem performansının yüksek olması hedeflenmiştir. $\mathrm{Bu}$ şekilde harmoniklere etkili bir şekilde müdahale edilmektedir. Sisteme ait ölçümler için gerilim bloğu yerleştirilerek değerler kaydedilmiştir. Filtreli ve filtresiz durumlara ait kayıtlar ayrı ayrı alınarak sistem analiz edilmiştir. Paralel filtreye üç faza ait anlık akım bilgileri üç fazlı akım-gerilim ölçüm bloğu ile sağlanmaktadır.

\subsection{Klasik Filtreleme Yöntemi}

Pasif filtreler Belirli harmonik frekanslarında ayarlanan filtrelerdir. Direnç, endüktans ve kapasitans gibi pasif devre elemanlarından oluşmaktadır. Belirlenen frekansta rezonans meydana getirilerek filtreleme gerçekleştirilmektedir. Bu fitreler sisteme parallel veya seri şekilde bağlanabilmektedir. Bu çalışmada paralel bağlantı kullanılmıştır. Pasif filtrede kalite faktörü filtrenin ayar karakteristiğini belirlemek için kullanılan bir parametredir. Bu filtreleme işleminde filtre tasarımı için öncelikle devrenin harmonik analizi yapılarak durum tespiti yapılmalıdır. Bu çalışmada çift ayarlı pasif filtre kullanılmış olup devre şeması şekil 6 ile verilmektedir. Çift sönümlü pasif filtre seri LC elemanları ile parallel RLC elemanlarının seri bağlantısından oluşmaktadır. $\mathrm{Bu}$ tip filtreleme işleminde tasarım için ilgili filtreleme frekansları, kalite faktörü ve reaktif güç gibi parametreler kullanılmaktadır. Filtreleme için ayrıca devrenin toplam empedansı ve rezonans frekansları dikkate alınmaktadır.

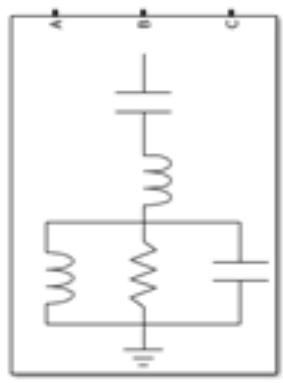

Şekil 6. Çift Sönümlü Pasif Filtre [MATLAB]

Durum tespitinin ardından saptanan frekanslar için harmonik filtreleme yapılmaktadır. Klasik filtrelemede durum statik kabul edildiği için dinamik koşullarda sistem harmoniklere maruz kalabilmektedir. Bu metot yük değişiminin sık rastlanmadığı durumlar için tercih edilmektedir.

\subsection{Harmonik Limitleri}

Harmonik limitleri ile ilgili olarak akım ve gerilim harmonikleri için IEC Std. 1000-3-4, EN 50006 ve IEEE-519-1992 standartları kullanılmaktadır. Bu standartlarda belirtilen THD değeri ile dalga şeklinde oluşan bozulma belirtilmektedir. Bundan ötürü THD değeri için belirlenen limitler dalgada gerçekleşebilecek bozulma miktarını sinırlandırmaktadır. Tablo 1 ile IEEE 519-1992 standardinda belirtilen harmonik limitleri verilmektedir. 
Tablo 1. IEEE 519-1992 gerilim harmoniğinine ait limitler

\begin{tabular}{|c|c|c|}
\hline $\begin{array}{c}\text { Bara } \\
\text { Gerilimi }\end{array}$ & $\begin{array}{c}\text { Maksimum } \\
\text { Bireysel } \\
\text { Harmonik Bileşen } \\
\text { (\%) }\end{array}$ & $\begin{array}{c}\text { Maksimum } \\
\text { THD (\%) }\end{array}$ \\
\hline$<69 \mathrm{kV}$ & 3.0 & 5.0 \\
\hline $69-161 \mathrm{kv}$ & 1.5 & 2.5 \\
\hline$\geq 161 \mathrm{kv}$ & 1.0 & 1.5 \\
\hline
\end{tabular}

1500 V DC beslemeli cer merkezinde uygulanan gerilim $1.22 \mathrm{kV}$ olduğu için tabloda bulunan 1.satıra ait bölüm uyulması gereken sınırı belirtmektedir. $\mathrm{Bu}$ sistem için uyulması gereken THD değeri \% 5 olarak açıklanmaktadır. $\mathrm{Bu}$ çalışma kapsamında gerilim harmoniği için filtreleme işlemi gerçekleştirilirken bu değerin altına inilmesi hedeflenerek başarı elde edilmiştir.

\section{BULGULAR}

Bu çalışma ile 1500 V DC Beslemeli Raylı Sistemlerde Gerilim Harmoniği Probleminin Paralel Aktif Güç Fitresi ve klasik yöntemlerle Çözümü yapılmıştır Benzetim için Matlab/Simulink programı kullanılmıştır. Tablo 2'de aktif filtre parametrelerine ait detaylı bilgi verilmektedir. Benzetim için $12 \mathrm{~km}$ uzunlukta 9 istasyonlu 8 trafo merkezli bir raylı sistem hattı kullanılmıştır. Gidiş dönüş olmak çift tünel yapısına sahip bir raylı sistem hattı tercih edilmiştir.
Tablo 2. Aktif Filtre Parametreleri

\begin{tabular}{|c|c|}
\hline Aktif Filtre Parametreleri & Değer \\
\hline Kaynak Gerilimi (V) & $1220 \mathrm{Vrms}$ \\
\hline Kaynak Frekansı (F) & $50 \mathrm{~Hz}$ \\
\hline Kaynak Empedansı $(\mathrm{R}, \mathrm{L})$ & $0.005 \Omega, 2.9 \mathrm{e}-5 \mathrm{H}$ \\
\hline Yük Empedansı & $\begin{array}{c}0.5 \Omega-6 \Omega \text { Aralığında } \\
\text { Değişken }\end{array}$ \\
\hline $\begin{array}{c}\text { Aktif Filtre Histerizis Bant } \\
\text { Aralığ }\end{array}$ & $0.1 \mathrm{~V}$ \\
\hline Aktif Filtre Empedansı & $2 \mathrm{e}-4 \mathrm{H}$ \\
\hline Aktif Filtre Kondansatörü & $1 e-6 \mathrm{~F}$ \\
\hline Güç Elektroniği Devresi & PWM IGBT Invertor \\
\hline Bağlantı Şekli & Devreye Paralel Bağlantı \\
\hline
\end{tabular}

Şekil 7 ile raylı sistem hattına ait benzetim ekranı verilmektedir. Aktif ve pasif filtreleme kaynak gerilimine an yakın nokta olan birinci trafo merkezinde yapılmıştır. Filtre bağlantısı için cer transformatörünün sekonder bağlantı noktası optimal nokta olarak belirlenmiştir. 1 den 9'a kadar atanan sayllar istasyon bölgelerini temsil etmektedir. $34.5 \mathrm{kV}$ Teiaş girişi 1 numaralı istasyon bölgesindeki cer merkezi üzerinden sisteme bağlanmıştır. DC cer merkezlerine gelen AC gerilim $34.5 \mathrm{kV}$ orta gerilim hattı üzerinden istasyonlara dağılmaktadır. Sistemde 8 adet cer merkezi bulunmakta olup tren hareketlerinin benzetimi oluşturulan hat blokları ile gerçekleştirilmektedir.

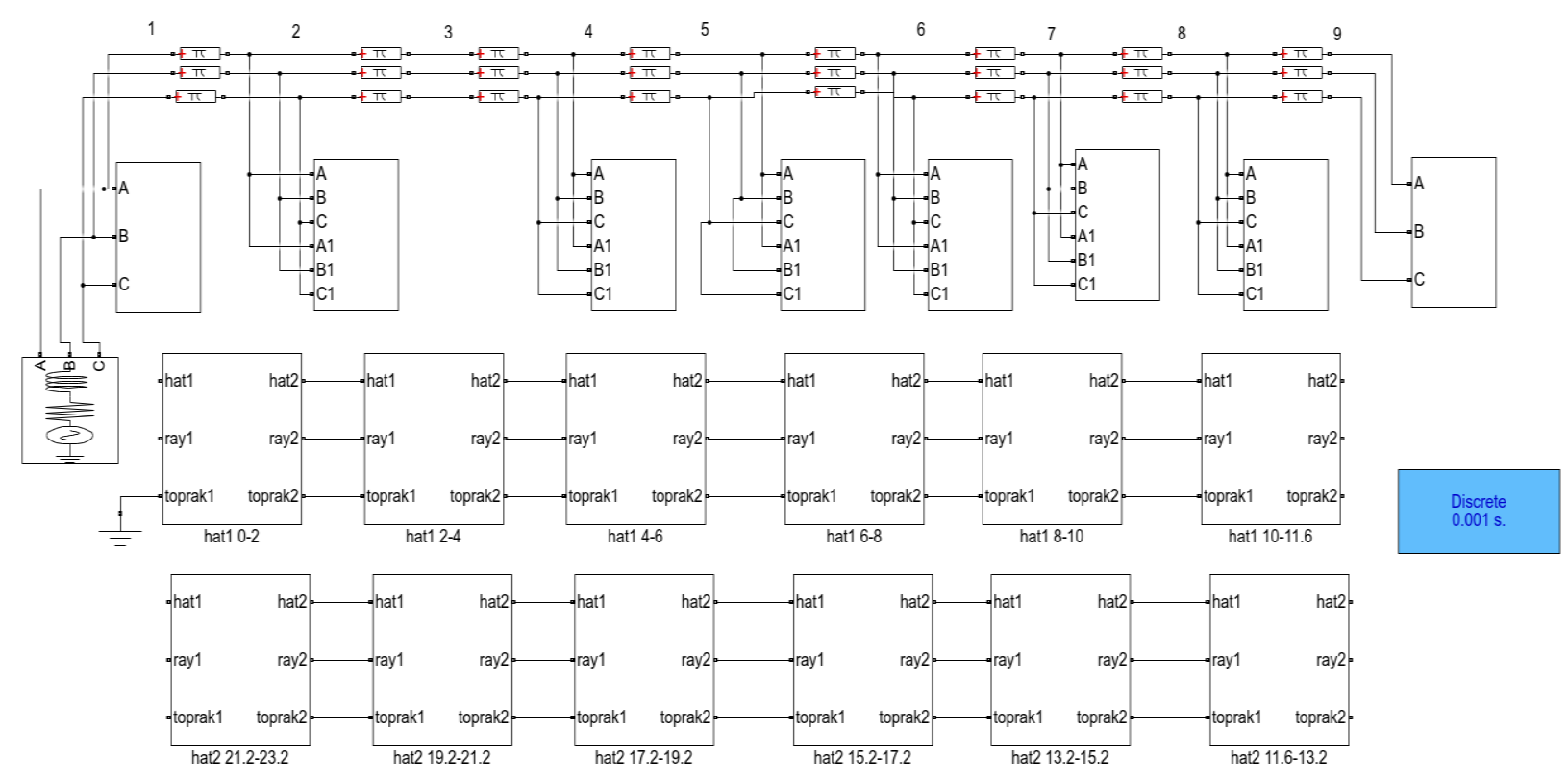

Şekil 7. Benzetim Ekranı

$\mathrm{Bu}$ şekilde sistem tarafından üretilen harmoniklerin şebekeye ulaşmadan ortadan kaldırılması hedeflenmiştir. Benzetim aktif filtreleme, pasif filtreleme ve filtresiz olmak üzere 3 ayrı durum için çalıştırılarak sistem test edilmiştir. Sistem çalışırken sonuçlar gerilim ölçüm noktasında kayıt edilmiştir. 


\subsection{Filtresiz Durumda Gerilim THD Değerinin Hesaplanması}

Sistemde filtreleme yapılmadığı durum için sistem çalıştırılarak sonuçlar kayıt altına alınmıştır. Bu durumda oluşan gerilimin dalga işareti şekil 8 ile gösterilmektedir. Görüldüğü üzere gerilimin değişimi 1900-2100 V aralığında gerçekleşmektedir. Bu durumda cer transformatörünün sekonder geriliminde önemli oranda bir bozulma yaşanmıștır.

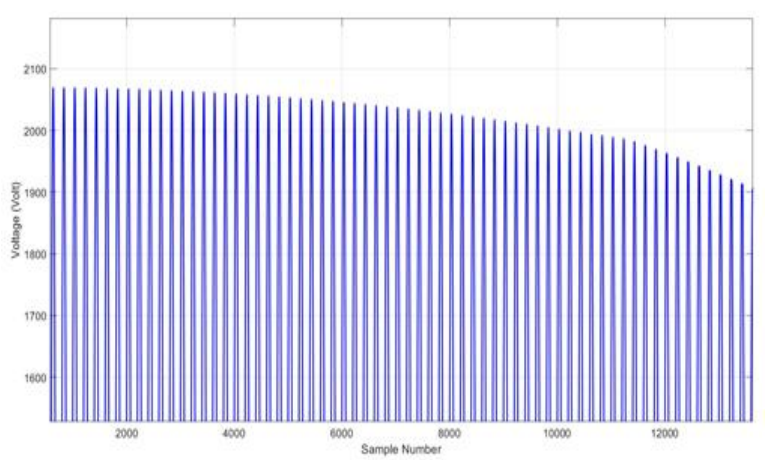

Şekil 8. Filtresiz Durumda Gerilim Sinyali

Bu duruma ait FFT (Hızlı Fourier Dönüşümü) analiz sonuçları aşağıda verilmektedir. $\mathrm{Bu}$ duruma ait sonuçlar şekil 9 ile verilmektedir.

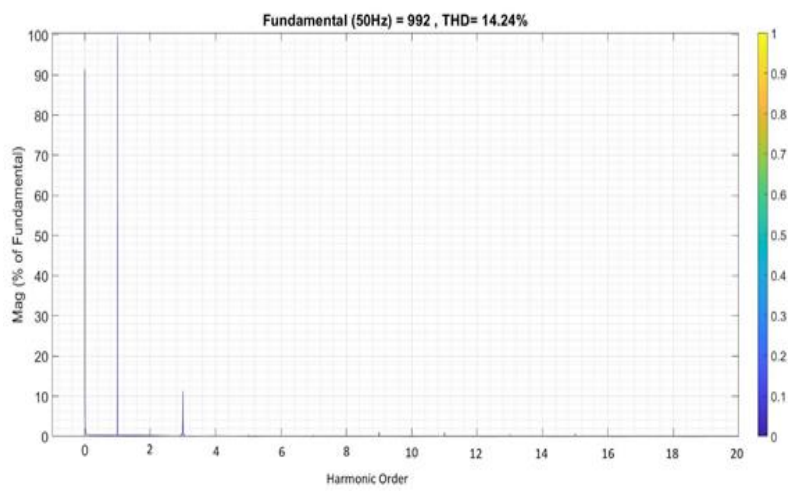

Şekil 9. Filtresiz Duruma ait FFT Analiz Sonuçları

$\mathrm{Bu}$ durumda gerilim harmoniği THD değeri \% 14.24 olmaktadır. Harmonik analizinde frekanslara bağlı olarak oluşan harmonikler saptanmıştır. Maksimum frekans $1000 \mathrm{~Hz}$ olarak seçilmiş̧ir.

\subsection{Pasif Filtreli Durumda Gerilim THD Değerinin Hesaplanması}

Pasif filtre sisteme paralel bağlandığ durumda sistem test edilmiştir. Bu durumda gerilime ait sinyal şekil 10 ile verilmektedir. Bu durumda gerilim değeri 1950$2000 \mathrm{~V}$ aralığında değişmektedir. Pasif filtreli durumda gerilim işareti incelendiğinde çıkış geriliminde önemli miktarda iyileşme gerçekleştirildiği anlaşılmaktadır.



Şekil 10. Pasif Filtreli Durumda Gerilim Sinyali

$\mathrm{Bu}$ duruma ait FFT analiz sonuçları frekanslara bağlı olarak aşağıda gibi olmaktadır. Sonuçlar şekil 11 ile gösterilmektedir.

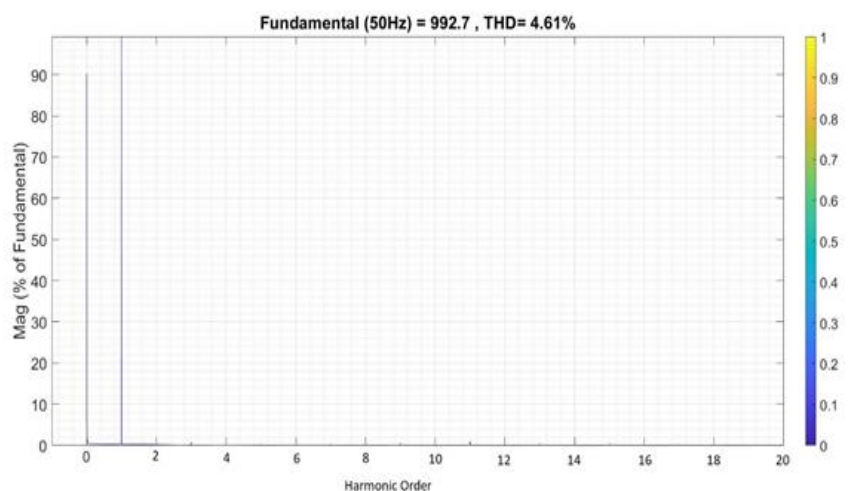

Şekil 11. Pasif Filtreli Duruma ait FFT Analiz Sonuçları

$\mathrm{Bu}$ durumda gerilim harmoniği THD değeri \% 4.61 olmaktadır. Pasif filtre çözümünde önemli miktarda iyileşme sağlanmıştır.

\subsection{Aktif Filtreli Durumda Gerilim THD Değerinin Hesaplanması}

Aktif filtre devreye paralel olarak bağlanarak sistem çalıştırılmıştır. Bu durumda oluşan gerilime ait dalga biçimi şekil 12 ile verilmektedir. Bu durum şartlarında gerilim değeri 1350-1400 V aralığında değişmektedir. Aktif filtreli durumda çıkış geriliminde başarılan iyileştirmenin pasif filtreye göre daha etkili olduğu görülmektedir.

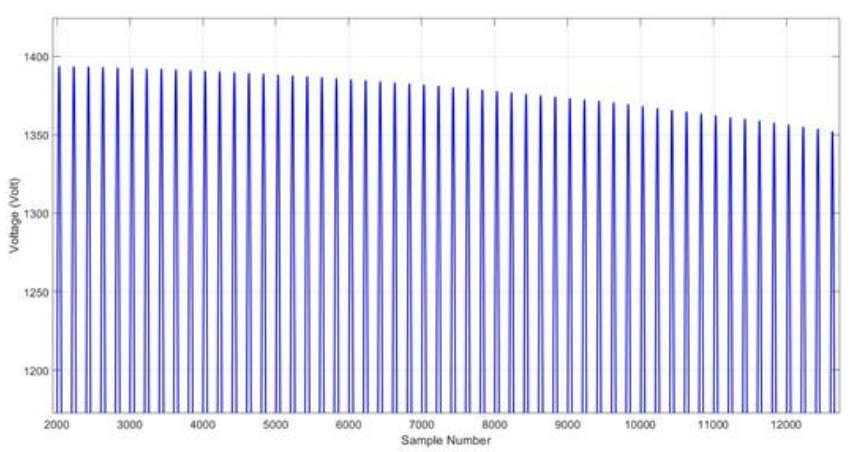

Şekil 12. Aktif Filtreli Durumda Gerilim Sinyali FFT analiz bu durum için de yapıldığında elde edilen 
sonuçlar frekanslara bağlı olarak aşağıda gibi olmaktadır. Şekil 13 ile elde edilen sonuçlar gösterilmektedir.

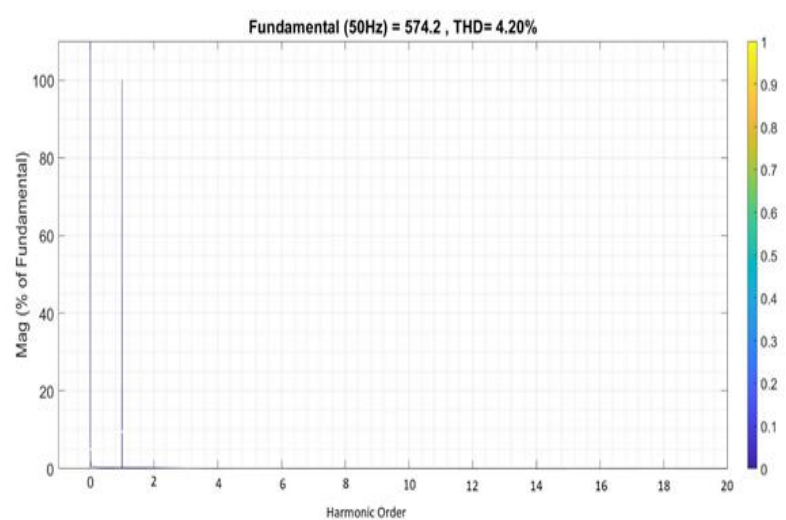

Şekil 13. Aktif Filtreli Duruma ait FFT Analiz Sonuçları

Bu durumda gerilim harmoniği THD değeri \% 4.20 olmaktadır. Aktif filtre uygulamasıyla önemli oranda iyileşme gerçekleştirilmiştir.

\subsection{Sonuçlara Ait Karşılaştırmalı Durum}

Çalışma sonunda elde edilen sonuçlara ait özet durum tablo 3 ile verilmektedir. İlgili çalışma şekline bağlı olarak aktif filtreli, pasif filtresiz ve sistemde filtreleme yapılmadığı koşullara ait özet durum burada verilmektedir.

Tablo 3. Aktif filtre, pasif filtre ve filtresiz koşullara ait özet durum

\begin{tabular}{|c|c|c|c|}
\hline $\begin{array}{c}\text { Devrenin } \\
\text { Çalışma } \\
\text { Durumu }\end{array}$ & $\begin{array}{c}\text { THD } \\
\text { değeri } \\
(\mathbf{\%})\end{array}$ & $\begin{array}{c}\text { İyileştirme } \\
\text { Oranı } \\
(\%)\end{array}$ & $\begin{array}{c}\text { IEEE } \\
\text { Standardına ait } \\
\text { Kriterlere } \\
\text { Uyum }\end{array}$ \\
\hline $\begin{array}{c}\text { Filtresiz } \\
\text { Durum }\end{array}$ & 14.24 & - & $\begin{array}{c}\text { Limitlerin } \\
\text { Dişında }\end{array}$ \\
\hline $\begin{array}{c}\text { Pasif Filtreli } \\
\text { Durum }\end{array}$ & 4.61 & 67 & Limitlerin İçinde \\
\hline $\begin{array}{c}\text { Aktif Filtreli } \\
\text { Durum }\end{array}$ & 4.20 & 70 & Limitlerin İçinde \\
\hline
\end{tabular}

Tabloda belirtildiği gibi filtre kullanılmadığında gerilim harmoniğine ait \% THD değeri limitlerin dışında kalmaktadır. Pasif filtre aktif filtre kullanıldığında ise gerilim harmoniği IEEE standardının izin verdiği limitlerin içinde değer almaktadır.

\section{SONUÇ VE DEĞERLENDİRME}

Bu çalışmada 1500 V DC Beslemeli Raylı Sistemler için gerilim harmoniği probleminin AGT Tabanlı Paralel Aktif Güç Fitresi ile Çözümü yapılmıştır. AGT ile zamanda oluşabilecek gecikmelerin önüne geçilmesi amaçlanmıştır. Aktif filtre ile klasik filtreleme yöntemleri karşılaştırılarak sonuçlar elde edilmiştir. Her duruma ait FFT analizi yapılarak gerilim grafiği örnekleme sayısına bağlı olarak verilmiştir.
Çalışma için 12 km uzunluğuna sahip 9 istasyonlu 8 cer merkezli bir raylı sistem hattına uygulama yapılmıştır. Aktif filtre ve pasif filtre devreleri sisteme paralel olarak bağlanırken bağlantı noktası olarak cer transformatörünün sekonder bağlantı bölümü seçilmiştir. Hattın orta gerilim besleme merkezine en yakın hatta uygulama yapılarak sistem çalıştırılmıştır. Sistem filtresiz durumda, pasif filtreli durumda ve aktif filtreli durumda olmak üzere ayrı ayrı çalıştırılarak sonuçlar kayıt altına alınmıştır. Sistemde sağlanan iyileştirme durumları anlatılarak IEEE'nin gerilim harmoniği ile ilgili standardıyla elde edilen sonuçlar karşılaştırılmıştır. Filtresiz durumda gerilim harmoniniği \% 14.24 THD değeri alırken pasif filtre bağlandığında bu değer \% 4.61 mertebelerine inmektedir. Aktif filtre bağlandığında ise bu değer \% 4.2 seviyesine kadar düşmektedir. Her iki filtreleme durumunda da IEEE'nin gerilim harmoniğiyle ilgili belirlediği limitlerin altına inilirken aktif filtreleme durumunda pasif filtreleme durumuna göre daha iyi sonuç elde edilmiştir. İki filtreleme yönteminde de önemli miktarda iyileşme sağlanmıştır. Bu çalışma ile DC beslemeli raylı sistemlerde gerilim düzensizliği probleminin çözümü için pasif filtrenin yanında yeni güç elektroniği teknolojilerini kapsayan bir uygulama olarak aktif filtre seçeneğinin daha iyi performans sonuçları sağladığı gösterilmiştir.

\section{KAYNAKLAR}

[1] Annapoorani, I., Samikannu, R., Senthilnathan, K., (2017). Series Active Power Filter for Power Quality Improvement Based on Distributed Generation. International Journal of Applied Engineering Research, 12, 12214-12218.

[2] Teixeira, N., F., Pinto, J., G., O., Freitas, M., J., S., Afonso, J., L., (2015). New Control Algorithm for Single-Phase Series Active Power Filter", Electric Power Components and Systems Journal, Taylor \& Francis Group, LLC, 43, 1752-1760.

[3] Bagde, A., P., Ambatkar, R., B., Bhure, R., G., Rakhonde, B., S., (2017). Power Quality Improvement By Series Active Power Filter- A Review. International Research Journal of Engineering and Technology, 4, 1730-1733.

[4] Kahraman, Ö., A., Sevim, D., Erkan, E., Çelebi, S., B., Cebeci, M., (2018). Reference Signal Estimation Methods for Parallel Active Power Filter Control. International Engineering and Technology Symposium, May, 1-7.

[5] Uçar, F., Coteli, R., Dandil, B., (2012). Three Level Inverter Based Shunt Active Power Filter Using MultiLevel Hysteresis Band Current Controller. Przegląd Elektrotechniczny (Electrical Review), 88, 227-231.

[6] Iswariya, T., Vennila, V., (2015). Design and Implementation of a Statcom for Railway Applications. Journal of Chemical and Pharmaceutical Sciences, 10, 137-142.

[7] Salem, M., Hamouda, M., Slama, J., B., H., (2017). Comparative Study of Conventional Modulation 
Schemes in Terms of Conducted And Radiated EMI Generated by Three-Phase Inverters. Turkish Journal of Electrical Engineering \& Computer Sciences, 25, 15991611.

[8] Akagi, H., (2005). Active harmonic filters,, Proc. IEEE, 12, 2128-2141.

[9] Hekimoğlu, B., Ekinci, S. , (2016). Paralel Aktif Güç Filtresi Denetimi İçin Adaline YSA Tabanlı Farkl Referans Akım Çıkartım Yöntemlerinin Karşılaștırılması. Journal of Life Sciences, 6, 219-237. [10] Akagi, H., Watanebe, E. H., Aredes, M., (2007). Instantaneous power theory and applications to power conditioning, New Jersey, USA, Wiley-IEEE Press.

[11] Fujita, H., Akagi, H., (1998). The unified power quality conditioner: The integration of series- and shunt-active filters. IEEE Trans. Ind. Electron, 2, 315322.

[12] Rüstemli, S., Cengiz, M., Dinçer, F., (2013). Elektrik Tesislerinde Harmoniklerin Aktif Filtre Kullanılarak Yok Edilmesi ve Simülasyonu. Bitlis Eren Üniversitesi Fen Bilimleri Dergisi, 2, 1, 30-38.

[13] Tuna, M, , Ergün, A., A., Kocabey, S., (2018). Mathematical modelling of PAF with voltage supply for non-linear loads By GSSA method. SAUJS, 22, 4, 1071-1079.

[14] Özçıra, S., (2018). Aktif Güç Filtrelerinin Temel Seçim Esaslarının Kompanze Edilmesi Gereken Büyüklüğe Göre Belirlenmesi. GUJS Part C., 6, 3, 691704.

[15] Gedikpınar, M. , GÜNGÖR, (2017). M. Bir-Fazlı İndüksiyon Motorlar İçin Paralel Aktif Güç Filtresi Tabanlı Reaktif Güç Kompanzasyonu". Frrat Üniversitesi Mühendislik Bilimleri Dergisi, 29, 2, 185 193 .

[16] Akçay M , Arifoğlu U., (2019). Anlık Güç Kuramı ile Dengesiz Yükler İçin SAGF Uygulaması. Haliç Üniversitesi Fen Bilimleri Dergisi, 2(1), 16-1.

[17]Anish, P.,S., Ramarajan, T., Srinivas, T., A., Sasikumar, M., (2012). Voltage Balancing in SVM
Controlled Diode Clamped Multilevel Inverter for Adjustable drives. International Journal of Soft Computing and Engineering, 1, 2231-2307.

[18] Kocaarslan, İ., Akçay, M., T., Akgündoğdu, A., Tiryaki, H., (2017). The comparison of the ANN and ANFIS methods for the prediction of voltage drop on an electric railway line. Journal of Electrical \& Electronics Engineering (IUJEEE), 18, 26-35.

[19] Akçay, M., T., Kocaarslan, İ., (2019). Determination Of Distance Between DC Traction Power Centers İn A $1500 \mathrm{~V}$ DC Subway Line With Artificial İntelligence Methods, Turkish Journal of Electrical Engineering \& Computer Sciences, 27, 289303.

[20] Kocaarslan, İ., Akçay, M., T., Akgündoğdu, A., Tiryaki, H., (2017). The comparison of the ANN and SVM Methods for the Prediction of Voltage Drop on a Subway Line, International Journal of Engineering Research and Advanced Development (IJERAD), 10, 57-65.

[21] Akçay, M., T., Kocaarslan, İ., (2019). Solving Power Quality Problem of $750 \mathrm{~V}$ DC Railway Substation With DSTATCOM Using SVPWM, (IJERAD), 11,2, 620-626.

[22] Kocaarslan, İ., Akçay, M., T., Ulusoy, S., E., Bal, E., Tiryaki, H., (2017). Creation of a dynamic model of the electrification and traction power system of a $25 \mathrm{kV}$ $\mathrm{AC}$ feed railway line together with the analysis of different operation scenarios using Matlab/Simulink, Turkish Journal of Electrical Engineering \& Computer Sciences, 25, 4254-4267.

[23] Jadeja, R., Patel, S., Chauhan, S., K., (2016). STATCOM - A Preface to Power Quality in Power Systems Performance. Engineering, Technology \& Applied Science Research, 1, 895-905.

[24] Akçay, M., T., Kocaarslan, İ., (2019). Simulation of Multi-Vehicle Signaling System with Matlab / Simulink and Design of Train Timetable, Journal of Science and Engineering, 2019, 6, 799-807. 